\title{
Construction of Artificial Islet Tissue with Functional Scaffolds for Stem Cells Differentiated into Insulin- Secreting Cells
}

\author{
Liping Liü, Jing Tan², Baoyuan $\mathrm{Li}^{2 *}$ and Qian xie ${ }^{2}$ \\ ${ }^{1}$ School of Chemical Engineering, Shanxi Datong University, China \\ ${ }^{2}$ School of Life Science, Shanxi Datong University, China
}

Submission: August 21, 2017; Published: August 23, 2017

*Corresponding author: Baoyuan Li, School of Life Science, Shanxi Datong University, China, Tel: +86 0-352-756-3032; Email: liby616@163.com

\begin{abstract}
The prevalence of diabetes has been increasing in recent years and become a threat to human health, now a days, islet replacement therapy is a widely accepted diabetes therapy. Tissue engineering, which involves implanting the scaffold compounded with seed cells and biological factors into the body, is a desirable technique to reconstruct the defective tissue. Embryonic stem cells, adult stem cells and induced pluripotent stem cells (iPSCs) offer the possibility of an unlimited source of cells to be differentiated into beta cells. Furthermore, there are numerous different materials available for scaffold manufacture including polyesters, naturally occurring proteins, extracellular matrix (ECM) and so on. Polylactic-co-glycolic acid (PLGA) is often used as the tissue engineering scaffold due to its good biocompatibility. In our study, fibroblasts and the extracellular matrix secreted by fibroblasts are used to effectively improve the biocompatibility of PLGA membrane and pancreatic stem cells, and promote the affinity between pancreatic stem cells and the PLGA membrane scaffold. The pancreatic stem cells grown on the fibroblastmodified PLGA membrane can be induced to differentiate into insulin secreting cells by the two-step induction method, and fibroblast-modified PLGA membrane plays a mechanical support role in the process of artificial islet tissue formation. The PLGA artificial islet tissue containing extracellular matrix of fibroblasts and insulin secreting cells can secrete insulin and reduce blood glucose within a short term in diabetic nude mice. Meanwhile, the Notch signaling system is closely related to the differentiation of pancreatic stem cells, our research also explores on the functional PLGA scaffold by altering the Notch ligands on fibroblast membrane, which would promote the differentiation of pancreatic stem cells.

Keywords: Bio-materials caffolds; Stem cells; Tissue engineering; Differentiation; Artificial islet tissue
\end{abstract}

Abbreviations: ISCs: Insulin-Secreting Cells; IPSCs: Induced Pluripotent Stem Cells; PLGA: Polylactic-Co-Glycolic Acid; ECM: Extracellular Matrix; VEGF: Vascular Endothelial Growth Factor; Hes-1: Hairy and Enhancer of Split-1; Ngn-3: Neurogenin-3; PDX-1: Pancreatic and Duodenal

\section{Introduction}

The prevalence of diabetes has been increasing in recent years and has become a threat to human health. Long term insulin injection can cause insulin resistance, and improper injection will lead to hypoglycemia and other complications [1]. All of these can significantly reduce the quality of life of patients with diabetes. At present, islet replacement therapy is a widely accepted diabetes therapy, whereby the disabled islets are replaced with whole organ transplantation or isolated and purified islet transplantation to achieve maintenance of normal blood glucose [2].

The pancreatic islet is mainly composed of endocrine cells such as insulin secreting cells, as well as connective tissue with abundant capillaries and nerve fibers. Therefore, it is feasible to construct artificial islet tissue by tissue engineering technique, which involves implanting the scaffold compounded with seed cells and biological factors into the body to reconstruct the defective tissue [3]. The interaction between seed cells and scaffold determines the success or failure of engineering tissue construction [4]. Embryonic and adult stem cells offer the possibility of an unlimited source of cells to be differentiated into beta cells moreover; iPSCs could be an alternative source of pluripotent stem cells [5]. But all these cells have the potential to become teratom as in vivo. Many studies suggested that pancreatic stem cells existing in islets or pancreatic ducts can be inducted to differentiate into ISCs, and this is an effective way to solve the shortage of islet donor [6,7].

There are numerous different materials available for scaffold manufacture including polyesters such as polylacticco-glycolic acid (PLGA) and poly-L-lactide acid, polyurethanes, 


\section{Current Research in Diabetes \& Obesity Journal}

polyanhydrides, naturally occurring proteins (collagen, elastin, fibrin), decellularized extra cellular matrix and so on $[8,9]$. PLGA copolymer, a type of biodegradable polymer material, has good biocompatibility and film forming properties, making it an excellent scaffold for tissue engineering [10]. Furthermore, an excellent cell scaffold needs to provide sufficient growth space for cell adhesion and extracellular matrix (ECM) deposition. Many studies modified the scaffolds to endow different physiological functions such as promoting cell growth, inducing cell differentiation and vascularization with endothelial cells or VEGF [10-12]. ECM proteins such as proteins include collagen, laminin, fibronectin, vitronectin, are substances that help create the micro niche in which cells reside [13]. The study has shown that mouse islets seeded within PLGA scaffolds and transplanted into diabetic mice displayed significantly improved function when the scaffold was coated with collagen IV. Time to euglycemia and response to glucose challenge were both significantly faster for collagen IV coated scaffolds compared with scaffolds coated with fibronectin, laminin or non-coated control scaffolds treated with serum containing media [14]. In our previous study, we used fibroblasts to modify the PLGA scaffolds, the ECM secreted by fibroblasts, which contains all of these proteins, effectively improve the histocompatibility and cell compatibility of the PLGA membrane, promoted the proliferation and differentiation of pancreatic stem cells [15].

In addition, the impact of the Notch signaling system on the differentiation of pancreatic stem cells is also worthy of attention. The Notch signaling pathway is essential for cellcell communication, guiding the cells towards proliferation or differentiation. The classical Notch signaling pathway is a combination of Notch receptors on some cells and ligands expressed on adjacent cells. Binding of a ligand to a Notch receptor causes sustained hydrolysis of the receptor, releasing its intracellular domain (NICD), which binds to CSL (a DNA binding protein), activating the expression of downstream genes, including hairy and enhancer of split-1 (Hes1) andneurogenin 3 (Ngn3). For pancreatic stem cells, if Hes1is highly expressed, the cells will maintain stem cell characteristics and have a tendency to differentiate into pancreatic ductal epithelial cells, whereas when Ngn3 is highly expressed, pancreatic stem cells differentiate into pancreatic endocrine cells [16]. Ngn3 is a transcription factor that belongs to the Neurogenin/NeuroD family of neuronal genes. It is not only a marker of pancreatic stem cells, but also an important factor influencing pancreatic stem cells to differentiate into pancreatic endocrine cells. It has been reported that initiating the expression of Ngn3 in the early islets of transgenic mice with the promoter pancreatic and duodenal homeobox 1 (PDX-1) can result in an increased number of endocrine cells in the pancreas and a decreased number of exocrine cells [17]. We can influence the expression of Notch receptor in pancreatic stem cells by the Notch ligand on the fibroblast membrane, and regulate the proliferation and differentiation of pancreatic stem cells through Notch signaling system. Our research have been also investigated the impact of the Notch signaling system on the differentiation of pancreatic stem cells by altering the Notch ligands on fibroblast membrane, and constructed functional PLGA scaffold which promote the differentiation of pancreatic stem cells.

The fatal impediment to the function of transplanted tissue is its rejection by the host immune system [18]. In addition to the damage of immune system, the successful of artificial islet tissue may be closely associated with the non-specific inflammatory response and blood-mediated transient inflammatory response of nude mice. Many studies suggested that cell necrosis and apoptosis have a significant impact on the effect of islet transplantation $[19,20]$. Therefore, the key technical problem of the construction of artificial islet tissue is to solve the immune system's response, non-specific inflammatory response, bloodmediated transient inflammatory response, as well as maintain the proliferation and differentiation of transplanted stem cells in vivo. Several types of macro-devices have been explored including planar membranes, hollow fibers and macro-capsules, but the field has predominantly concentrated on the development of microencapsulation of cells [21]. However, microencapsulation not only affects cell proliferation and differentiation, but also partially limits the function of cells. Moreover, utilizing the autologous cells as a tissue source is alternative means of avoiding immune rejection.

\section{Discussion}

Our studies demonstrated that the fibroblasts and the ECM secreted by fibroblast scan effectively improve the biocompatibility of PLGA membrane and pancreatic stem cells, and promote the affinity between pancreatic stem cells and the PLGA membrane scaffold [15]. The pancreatic stem cells grown on the fibroblast-modified PLGA membrane can be induced to differentiate into insulin secreting cells by the two-step induction method, the PLGA artificial islet tissue containing ECM of fibroblasts and insulin secreting cells can secrete insulin and reduce blood glucose within a short term in diabetic nude mice [15]. Fibroblast-modified PLGA membrane plays a mechanical support role in the process of artificial islet tissue formation; however, non-specific inflammatory response is the main cause in primary non-function of islet transplantation [15]. Hence, the research on artificial islet tissue derived from non-antigenic autologous stem cells will have a profound effect on the treatment of diabetes. We can use the ECM secreted from autologous fibroblasts as a scaffold to improve the anti-inflammatory and anti-immune properties of the artificial islet tissue.

\section{Conclusion}

As the development of the understanding for the mechanisms underlying the proliferation and differentiation of ISCs in vitro and in vivo, more and more research has been focused on stem cell based therapies towards the clinic, the ISCs the rapiesusing stem cells as a replacement will no doubt benefit from the 
technological advances made in the fields of bioengineering and biomaterials. The successful induction from stem cells to ISCs is a multi-factorial process. It requires appropriate ECM combination for cellular adhesion and differentiation, correct growth factors for timely induction, and specific culture medium for cell growth at various stages of development in vitro and in vivo. Furthermore, there are abundant vascular and nerve fibers in the islets, and there are a lot of same markers for pancreatic stem cells and neural stem cells, such as Nestin, Hes, and Ngn, which are regulated by the Notch signaling system. Many studies have shown that pancreatic capillary endothelial cells and nerve fibers had effectively regulated the growth and differentiation of islet endocrine cells. Therefore, it is meaningful to construct the angiogenic and innervated artificial islet.

\section{References}

1. Katsarou A, Gudbjörnsdottir S, Rawshani A, Dabelea D, Bonifacio E, et al. (2017) Type 1 diabetes mellitus. Nat Rev Dis Primers 30(3): 17016.

2. Ramiya VK, Maraist M, Arfors KE, Schatz DA, Peck AB, et al. (2000) Reversal of insulin-dependent diabetes using islets generated in vitro from pancreatic stem cells. Nat Med 6(3): 278-282.

3. Soria B, Gauthier BR, Martín F, Tejedo JR, Bedoya FJ, et al. (2015) Using stem cells to produce insulin. Expert Opin Biol Ther 15(10): 14691489.

4. Van der Smissen A, Hoffmeister PG, Friedrich N, Watarai A, Hacker MC, et al. (2017) Artificial extracellular matrices support cell growth and matrix synthesis of human dermal fibroblasts in macroporous 3D scaffolds. J Tissue Eng Regen Med 11(5): 1390-1402.

5. Fazili A, Gholami S, Minaie Zangi B, Seyedjafari E, Gholami M (2016) In vivo differentiation of mesenchymal stem cells into insulin producing cells on electrospun Poly-L-Lactide acid scaffolds coated with matricariachamomilla L. oil. Cell J 18(3): 310-321.

6. Noguchi H, Naziruddin B, Jackson A, Shimoda M, Ikemoto T, et al. (2010) Characterization of human pancreatic progenitor cells. Cell Transplant 19(6): 879-886.

7. TuchBE, Gao SY, Lees JG (2014) Scaffolds for islets and stem cells differentiated into insulin-secreting cells. Front Biosci (Landmark Ed) 19(1): 126-38.

8. Fang RH, Jiang Y, Fang JC, Zhang L (2017) Cellmembrane-derived nanomaterials for biomedical applications. Biomaterials 128: 69-83.

9. Perisic T, Zhang Z, Foehr P, Hopfner U, Klutz K, et al. (2017) Biodegradable poly (lactic acid-co-glycolic acid) scaffolds as carriers for genetically-modified fibroblasts. PLoS One 12(4): e0174860.
10. Mao GH, Chen GA, Bai HY, Song TR, Wang YX (2009) The reversal of hyperglycaemia in diabetic mice using PLGA scaffolds seeded with islet-like cells derived from human embryonic stem cells. Biomaterials 30(9): 1706-1714.

11. Braam SR, Zeinstra L, Litjens S, Ward van Oostwaard D, van den Brink $\mathrm{S}$, et al. (2008) Recombinant vitronectin is a functionally defined substrate that supports human embryonic stem cell self-renewal via alphavbeta 5 integrin. Stem Cells 26(9): 2257-2265.

12. Kaufman Francis K, Koffler J, Weinberg N, Dor Y, Levenberg S (2012) Engineered vascular beds provide key signals to pancreatic hormoneproducing cells. PLoS One 7(7): e40741.

13. Labriola L, Montor WR, Krogh K, Lojudice FH, Genzini T, et al. (2007) Beneficial effects of prolactin and laminin on human pancreatic isletcell cultures. Mol Cell Endocrinol 263(1-2): 120-133.

14. Salvay DM, Rives CB, Zhang X, Chen F, Kaufman DB, et al. (2008) Extracellular matrix protein-coated scaffolds promote the reversal of diabetes after extrahepatic islet transplantation. Transplantation 85(10): 1456-1464.

15. Liu LP, Tan J, Li BY, xie Q, Sun JW, et al. (2017) Construction of functional pancreatic artificial islet tissue composed of fibroblastmodified polylacticco-glycolic acid membrane and pancreatic stem cells. J Biomater Appl 1: 885328217722041.

16. Koblas T, Leontovyc I, LoukotovaS,Kosinova L, Saudek F (2016) Reprogramming of pancreatic exocrine cells AR42J into insulinproducing cells using mRNAs for Pdx1, Ngn3, and MafA transcription factors. Mol Ther Nucleic Acids 17(5): e320.

17. Cai Q, Bonfanti P, Sambathkumar R,Vanuytsel K,Vanhove J (2014) Prospectively isolated NGN3-expressing progenitors from human embryonic stem cells give rise to pancreatic endocrine cells. Stem Cells Transl Med 3(4): 489-499.

18. Ozmen L, Ekdahl KN, Elgue G, Rolf Larsson, Olle Korsgren (2002) Inhibition of thrombin abrogates the instent blood-mediated inflammatory reaction triggered by isolated human islets: possible application of the thrombin inhibitor melagatran in clinical islet transplantation. Diabetes 51(6): 1779-1784.

19. Jaeger C, Brendel MD, Hering BJ (1997) Progressive islet graft failure occurs significantly early in autoantibody-positive than in autoantibody-negative IDDM recipients of intrahepatic islet allografts. Diabetes 46(28): 1907-1910.

20. Shapiro AM, Lakey JR, Ryan EA, Korbutt GS, Toth E, et al. (2000) Islet transplantation in seven patients with type 1 diabetes mellitus using a glucocorticoid-free immunosuppressive regimen. N Engl J Med 343(4): 230-238.

21. Lacik I (2006) Polymer chemistry in diabetes treatment by encapsulated islets of langerhans: review to 2006. Australian Journal of Chemistry 59(8): 508-524.

\begin{tabular}{l} 
Your next submission with Juniper Publishers \\
will reach you the below assets \\
- Quality Editorial service \\
- Swift Peer Review \\
- Reprints availability \\
- E-prints Service \\
- Manuscript Podcast for convenient understanding \\
- Global attainment for your research \\
- Manuscript accessibility in different formats \\
( Pdf, E-pub, Full Text, Audio) \\
- Unceasing customer service \\
Track the below URL for one-step submission \\
https://juniperpublishers.com/online-submission.php \\
\hline
\end{tabular}

